Revista Brasileira de Agricultura Irrigada v.10, nº.5, p. 883 - 892, 2016

ISSN 1982-7679 (On-line)

Fortaleza, CE, INOVAGRI - http://www.inovagri.org.br

DOI: $10.7127 /$ rbai.v10n500458

Protocolo 458.16 - 10/08/2016 Aprovado em 14/10/2016

\title{
EVAPOTRANSPIRAÇÃO DE REFERÊNCIA E COEFICIENTE DE CULTIVO DA PIMENTEIRA NO AGRESTE ALAGOANO
}

Célia Silva dos Santos ${ }^{1}$, Daniella Pereira dos Santos ${ }^{2}$, Wanderson José de Oliveira ${ }^{3}$, Paulo Ferreira da Silva ${ }^{4}$, Márcio Aurélio Lins dos Santos ${ }^{5}$, Angela Jessyka Pereira Brito Fontenele ${ }^{6}$

\section{RESUMO}

O conhecimento das necessidades hídricas das culturas é imprescindível no manejo de irrigação. Com isso o objetivo deste trabalho foi determinar a evapotranspiração de referência e o coeficiente de cultivo para cultura da pimenta malagueta usando a lisimetria de drenagem em ambiente protegido e em campo. Foram instalados seis lisímetros de drenagem em duas áreas experimentais, no período de fevereiro a maio de 2013 no campus da Universidade Federal de Alagoas. O coeficiente de cultivo foi determinado pela razão entre a evapotranspiração da cultura e a evapotranspiração de referência, sendo a evapotranspiração de referência estimada pelos métodos de Penman-Montheith (FAO-56) e Hargreaves-Samani e a evapotranspiração da cultura determinada com os lisímetros de drenagem. O método de Hargreaves-Samani subestima a evapotranspiração de referência e para seu uso deve ser feito o ajuste com a equação obtida nesse trabalho. A determinação do coeficiente de cultivo pelo método de Hargreaves-Samani apresentou resultados subestimados nas duas áreas. Pode-se adotar os valores de coeficiente de cultivo determinados para o manejo da irrigação da pimenta malagueta para a região de Arapiraca-AL.

Palavras-chave: lisímetro, irrigação, Capsicum frutescens L.

\section{REFERENCE EVAPOTRANSPIRATION AND CROP COEFFICIENT OF CHILI PEPPER IN THE AGRESTE ALAGOANO}

\begin{abstract}
Knowledge of crop water requirements is essential in the management of irrigation. With this the objective of this study was to determine the reference evapotranspiration and the crop coefficient for chilli pepper culture using lysimeter drainage in greenhouse and field. Six drainage lysimeters were installed in two areas, from february to may 2013 on the campus of

\footnotetext{
${ }^{1}$ Doutoranda em Engenharia Agrícola, UFRPE, 52171-900, Recife-PE, celia@agro.eng.br

2Doutoranda em Engenharia Agrícola, UFRPE, 52171-900, Recife-PE, daniellapsantos@hotmail.com

${ }^{3}$ Doutorando em Engenharia Agrícola, UFRPE, 52171-900, Recife-PE, w.joliveira@yahoo.com.br

${ }^{4}$ Doutorando em Irrigação e Drenagem, UNESP, 18618-970, São Paulo-SP, pauloagrom@gmail.com

${ }^{5}$ Professor Adjunto IV, UFAL/Campus Arapiraca, 57309-005, Arapiraca-AL, mal.santo@hotmail.com

${ }^{6}$ Doutoranda em Engenharia Agrícola, UFRPE, 52171-900, Recife-PE, jessikafontenele@hotmail.com
} 
the Federal University of Alagoas. The crop coefficient was determined by the ratio between crop evapotranspiration and reference evapotranspiration, being the reference evapotranspiration estimated by the methods of Penman-Montheith (FAO-56) and Hargreaves-Samani and the crop evapotranspiration with drainage lysimeters. The Hargreaves-Samani method underestimates the reference evapotranspiration and its use must be made fit to the equation obtained in this study. The determination of crop coefficient for Hargreaves-Samani method presented underestimated results in two areas. Can be adopt the crop coefficient determined for the management in chilli pepper irrigation for Arapiraca-AL.

Keywords: lysimeters, irrigation, Capsicum frutescens L.

\section{INTRODUÇÃO}

A Pimenta (Capsicum frutescens L.) é um dos vegetais mais cultivados no mundo. A produção mundial de pimenta fresca é de aproximadamente 31 milhões de toneladas, tendo como maiores produtores a China, o México e Turquia com produção aproximada de $11,1,7$ e 1,6 milhões de toneladas respectivamente no ano de 2013 (FAOSTAT, 2016).

As pimentas (Capsicum spp.) compõem uma importante parte do mercado de hortaliças frescas do Brasil (DUTRA et al., 2010). Segundo Pozobon et al. (2011), o cultivo de pimentas ocorre praticamente em todas as regiões brasileiras.

Para o melhor rendimento na produção de pimenta um abastecimento de água adequado é necessário durante todo o período de crescimento (PANDEY et al., 2012). Isso pode ser alcançado com o uso da irrigação. $O$ sistema de cultivo e o manejo da irrigação tem sido determinante para o rendimento satisfatório da pimenteira no Sul, Sudeste, Centro Oeste e Nordeste do país (LIMA et al., 2013).

O sucesso na agricultura irrigada depende de inúmeras variáveis (PAES et al., 2012). Para isso, é necessário que se tenham informações precisas sobre parâmetros básicos, como: a evapotranspiração de referência (ETo), a evapotranspiração da cultura (ETc) e o coeficiente da cultura (Kc) (CHAVES et al., 2005).

A Organização para a Alimentação e Agricultura das Nações Unidas (ONU), possui publicada diretrizes para estimar a demanda hídrica das culturas, onde o método de
Penman-Monteith-FAO para a estimativa da ETo é considerado o método padrão (ALLEN et al., 1998). Porém, as variáveis necessárias à equação de Penman-Monteith nem sempre estão acessíveis ao produtor (COSTA et.al., 2010). Em condições como essas, pode-se utilizar modelos de estimativa de ETo que empreguem um menor número de variáveis, como o de Hargreaves (ALLEN et al., 1998).

Para a determinação do Kc, faz-se necessário então, a aplicação de algum método para estimar e ou medir a evapotranspiração de referência (ETo) e que se tenha conhecimento da evapotranspiração da cultura (ETc) em todas as suas fases de desenvolvimento (MIRANDA et al., 2016). A evapotranspiração da cultura (ETc) pode ser determinada por métodos diretos e indiretos, dos métodos diretos, o procedimento mais preciso para determinar a ETc é a utilização de lisímetros (FIGUEIRÊDO et al., 2009).

Poucos estudos sobre estimativa de necessidade hídrica em pimenta malagueta são relatados na literatura, particularmente sob condições do agreste nordestino. Com isso o objetivo deste trabalho foi determinar o coeficiente de cultivo (Kc) para cultura da pimenta malagueta usando a lisimetria de drenagem em ambiente protegido e em campo em Arapiraca-AL.

\section{MATERIAL E MÉTODOS}

O experimento foi conduzido na área experimental do Campus de Arapiraca da Universidade Federal de Alagoas $\left(9^{\circ} 45^{\prime} \mathrm{S}, 36^{\circ}\right.$ $39^{\prime} \mathrm{W}$ ), em condições de campo, nos meses de fevereiro a maio de 2013. O solo do local da 
pesquisa é caracterizado como Argissolo Vermelho Distrófico (EMBRAPA, 2013). Segundo a classificação de Köppen, o clima da região é do tipo 'As', tropical.

Os dados diários de precipitação pluvial de Arapiraca-AL, referente à época correspondente à condução do experimento, foram obtidos a partir de estação agroclimatológica automática instalada na área em estudo, que se encontram apresentados na Figura 1.

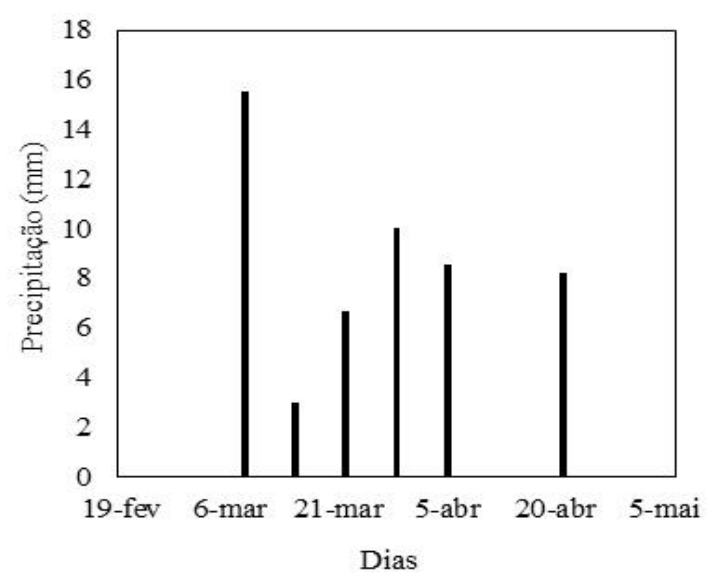

Figura 1. Precipitação pluvial (P), durante o período de condução do experimento.

Foram utilizados seis lisímetros de drenagem circular de material polietileno, instalados na área experimental, sendo três lisímetros em condições de ambiente protegido e três lisímetros em condições de campo. Cada tanque lisimétrico correspondeu a $0,80 \times 0,40$ $\mathrm{m}$, obtendo uma área de exposição de aproximadamente $0,125 \mathrm{~m}^{2}$, sendo a profundidade de $0,80 \mathrm{~m}$.

Para a instalação de cada lisímetro de drenagem foram realizadas escavações manuais das trincheiras com dimensões de 3,0 x 0,70 m, tomando-se o cuidado de separar o solo em quatro camadas de $0,20 \mathrm{~m}$.

Os lisímetros foram colocados nivelados com suave declive no sentido do dreno, e antes de serem preenchidos com o solo, foi colocada uma camada de $0,10 \mathrm{~m}$ de espessura de brita no fundo da caixa. Depois, os lisímetros foram preenchidos com o solo, obedecendo aos perfis originais do local. O sistema de drenagem dos lisímetros foi constituído de um tubo de PVC de $32 \mathrm{~mm}$ de diâmetro, conectado a um vaso de capacidade de 20 litros, em poço de observação posicionados a uma pequena declividade no sentido do dreno, no qual o excesso de água percolado era captado e medido.

A área do experimento foi dimensionada para três linhas contendo sete plantas em cada linha formando uma população total de vinte e uma plantas. Os três lisímetros foram instalados na segunda linha que corresponde a linha central da área. As mudas de pimenta malagueta foram transplantadas, aos 60 dias após a semeadura.

As irrigações foram realizadas por gotejamento, buscou-se elevar a umidade do solo à condição de capacidade de campo, sendo o manejo da irrigação executado em função da contabilização de entrada e saída de água do sistema lisimétrico. A mensuração da água coletada dos drenos foi realizada com o auxílio de uma proveta graduada de um litro, em uma frequência diária tendo início sempre às 8:00 hs e término às 9:00 hs da manhã.

Dados de radiação solar, temperatura e umidade relativa do ar, velocidade do vento, pressão atmosférica e precipitação, foram coletados através de uma estação meteorológica automática, modelo (Thies Clima) e utilizados para a estimativa da evapotranspiração de referência (ETo) pelos métodos de Penman-Monteith (FAO-56) com parametrização proposta por Allen et al. (1998) e Hargreaves-Samani (PERREIRA et al., 1997).

Os valores da evapotranspiração de referência pelo método de PenmanMonteith (ETo-PM) foram calculados segundo a equação 1 parametrizada proposta por (ALLEN et al., 1998). 


$$
E T o_{P M}=\frac{0,408 \Delta(R n-G)+\gamma \frac{900}{\text { Tmed }+273,16} U_{2} *(e s-e a)}{\Delta+\gamma\left(1+0,34 U_{2}\right)}
$$

em que: ETopm é a evapotranspiração de referência pelo método de FAO-PenmanMonteith, mm.dia ${ }^{-1}$; Rn é o saldo de radiação à superfície, $\mathrm{MJ} \mathrm{m}^{-2} \mathrm{dia}^{-1}$; $\mathrm{G}$ é o fluxo de calor no solo, $\mathrm{MJ} \mathrm{m} \mathrm{m}^{-2} \operatorname{dia}^{-1} ; \Delta$ é a declividade da curva de pressão de vapor de saturação, $\mathrm{kPa}^{\circ} \mathrm{C}^{-1}$; $\mathrm{U}_{2}$ é a velocidade do vento (média diária) a $2 \mathrm{~m}$ de altura, $\mathrm{m} \mathrm{s}^{-1}$; Tmed é temperatura média do ar,
${ }^{\circ} \mathrm{C}$; e é é a pressão de saturação do vapor, $(\mathrm{kPa})$; $e_{a}$ é a pressão real do vapor, $(\mathrm{kPa}) ; \gamma$ é a constante psicrométrica, $\mathrm{MJ} \mathrm{Kg}^{-1}$. Considera-se o valor de $G=0$.

Os valores da evapotranspiração de referência pelo método de Hargreaves-Samani (ETo HS) foram calculados segundo a equação 2 proposta por Pereira et al. (1997).

$$
E T o_{H S}=0,0023(T m+17,8) \sqrt{T \max -T \min } * R a * 0,408
$$

em que: EToнs é a evapotranspiração de referência, mm.dia ${ }^{-1}$; Ra é a radiação solar no topo da atmosfera, mm.d $\mathrm{d}^{-1}$; Tm é a temperatura média diária, ${ }^{\circ} \mathrm{C}$; Tmax é a temperatura máxima, ${ }^{\circ} \mathrm{C}$;

Tmin é a temperatura mínima, ${ }^{\circ} \mathrm{C} ; 0,408$ é o fator de conversão da radiação solar de $\mathrm{MJ} \mathrm{m}^{-2}$ para mm.dia ${ }^{-1}$.

A irrigação foi realizada diariamente, e as lâminas de irrigação foram estimadas com base no balanço hídrico do lisímetro de drenagem e $50 \%$ do Kc, para que o lisímetro sempre se mantenha em drenagem frequente, sendo o mesmo de acordo com sua fase fenológica segundo a equação 3 .

$$
L a=(I-D) *(F C * K c)+D
$$

em que: La é a lâmina aplicada, mm; I é a irrigação, mm; D é o drenado, mm; Fc é o fator de correção, $50 \%$ do Kc; Kc é o coeficiente de cultura da pimenta variando de acordo com a fase fenológica, adimensional.

A evapotranspiração da cultura (ETc) foi obtida através de medidas diretas nos drenos dos lisímetros de acordo com (ABOUKHALED et al., 1982) que estabelece a seguinte equação 4.

$$
E T C=(P+I-D) / A
$$

em que: ETc é a evapotranspiração da cultura, $\mathrm{mm}$; P é a precipitação pluviométrica, $\mathrm{mm}$; I é a lâmina de água aplica por irrigação, mm; D é a água drenada do lisímetro, mm; A é a área do lisímetro, $\mathrm{m}^{2}$.

A evapotranspiração da cultura obtida corresponde a uma média de 5 dias, e depois foi convertida em evapotranspiração diária $\left(\mathrm{mm} \cdot \mathrm{dia}^{-1}\right)$. A partir da ETo e dos valores de ETc, foram determinados os coeficientes de cultivo para cada condição experimental, pela relação entre a ETc, obtida pelo balanço de água nos lisímetros, e a ETo de PenmanMonteith e Hargreaves-Samani proposta pela equação 5.

$$
K c=\frac{E T c}{(E T o)}
$$

em que: Kc é o coeficiente da cultura, adimesional; ETc é a evapotranspiração da cultura, mm.dia ${ }^{-1}$; ETo é a evapotranspiração de referência, mm.dia ${ }^{-1}$.

\section{RESULTADOS E DISCUSSÃO}

Em relação à evapotranspiração de referência (ETo), pode-se observar na Figura 2, a dispersão obtida entre os valores estimados de ETo pelos métodos de Penman-Monteith (FAO-56) e Hargreaves-Samani. 


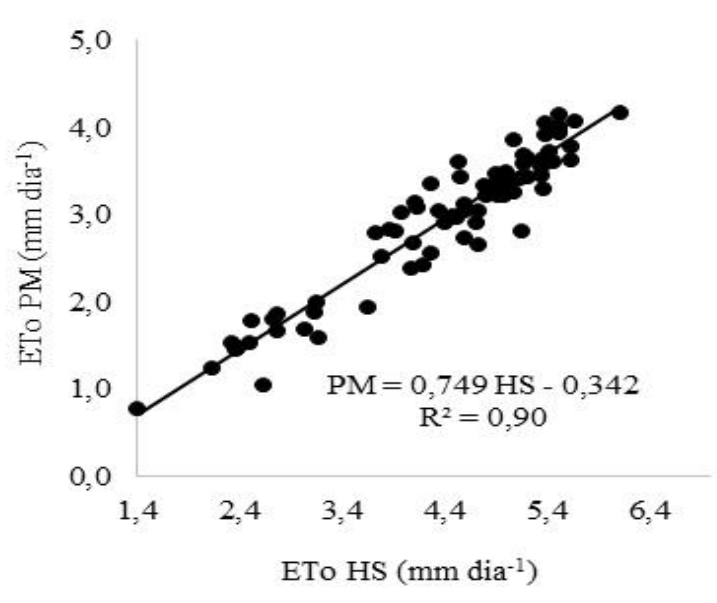

Figura 2. Correlação entre os valores diários da evapotranspiração de referência $\left(\mathrm{mm}^{\mathrm{d}} \cdot \mathrm{dia}^{-1}\right)$ estimados pelos métodos Penman-Monteith(PM) (FAO-56) e Hargreaves-Samani (HS).

Nota-se um alto valor do coeficiente de determinação $\left(r^{2}=0,90\right)$ e alto coeficiente de correlação $(r=0,95)$ indicando a precisão das estimativas para os métodos avaliados. Corroborando com Gonçalves et al. (2009) trabalhando na região de Sobral, semiárido do Ceará que encontraram desempenho muito bom para o método de Hargreaves-Samani para estimar a ETo da região. Silva et al. (2015) concluíram que quando se dispõem apenas de dados de temperatura do ar o método de Hargreaves-Samani pode ser utilizado para a estimativa da evapotranspiração de referência em substituição ao método padrão PenmanMonteith.

Silva et al. (2015) recomendam o uso do método de Hargreaves-Samani para cidades do semiárido do Ceará com bom índice de confiança. Silva et al. (2006) trabalhando no semiárido da Bahia também encontraram que o método de Hargreaves-Samani pode ser usado para estimar a ETo com boa correlação com o método de Penmam-Monteith.

O coeficiente angular da equação na Figura 2 apresenta valor menor que 1, indicando que os valores contidos no eixo $\mathrm{x}$ (ETo HS) são menores que os contidos no eixo y (ETo PM), evidenciando uma subestimação dos valores de ETo pelo método de Hargreaves-Samani.

Essa equação então pode ser utilizada para corrigir os valores de ETo obtidos pelo método de Hargreaves-Samani para a região estudada. Lima Junior et al. (2016) encontraram que o método de HargreavesSamani subestima a ETo no semiárido cearense. Bezerra et al. (2014) em Mossoró RN também encontraram que o método de Hargreaves-Samani subestima a ETo em relação ao método padrão, principalmente nos períodos mais secos e de elevada temperatura do ar.

Na Figura 3, pode-se observar detalhadamente a evapotranspiração de referência (ETo), observando-se o comportamento temporal com valores estimados pelos métodos Penman-Monteith (FAO-56) e Hargreaves-Samani no período do estudo.

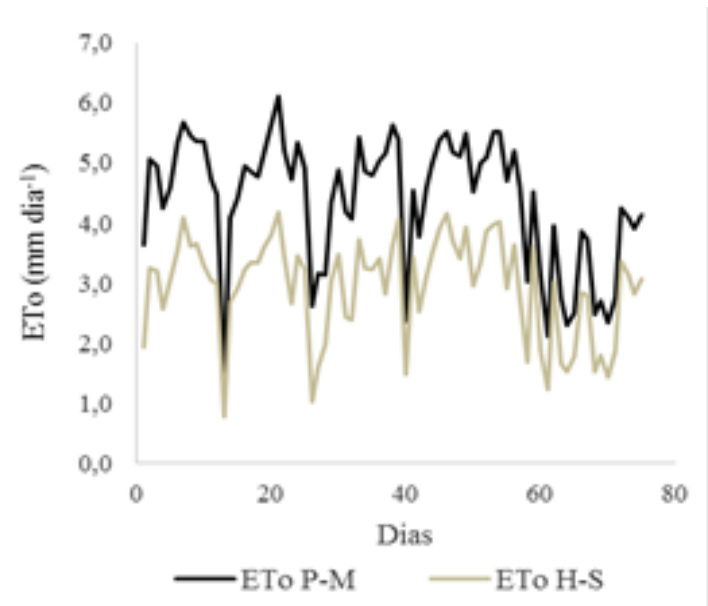

Figura 3. Variação temporal da evapotranspiração de referência (ETo) estimados pelos métodos Penman-Monteith (FAO-56) e Hargreaves-Samani em Arapiraca-AL.

Os valores da evapotranspiração de referência (ETo) estiveram sempre em paralelo durante todo o período de experimentação, com o valor médio de 4,38 mm.dia ${ }^{-1}$, máximo de 6,11 $\mathrm{mm}$ aos 22 DAT e mínimo de 1,38 mm aos 14 DAT para o método de PenmanMonteith (FAO-56). Quando estimada pelo método de Hargreaves-Samani, a evapotranspiração de referência obteve um valor médio de 2,97 mm.dia ${ }^{-1} \quad(35 \%$ de redução), máximo de 5,84 mm aos 28 DAT e mínimo de 0,76 mm aos 13 DAT. Essa redução ressalta a importância do uso da equação de ajuste determinada nesse trabalho, sem a qual a 
subestimação do valor da ETo pode ocasionar um fornecimento de água menor do que a planta realmente necessita.

A ETo apresentou grande variabilidade durante a condução do experimento. Segundo Barroca et al. (2015) dependendo do local, estação do ano e, até mesmo, de fenômenos meteorológicos atípicos, esse comportamento pode ocorrer.

Os resultados referentes à evapotranspiração da cultura (ETc) da pimenteira em condições de campo e ambiente protegido, encontram-se na Figura 4.

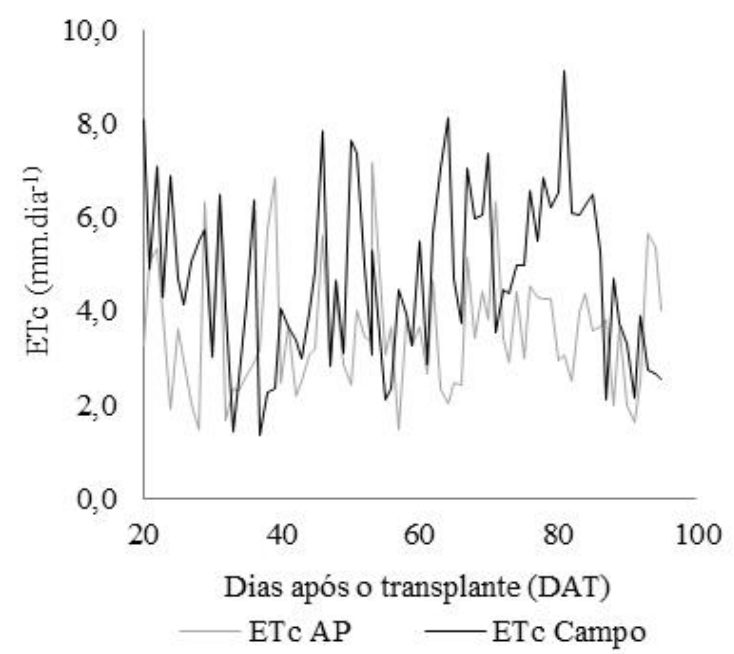

Figura 4. Variação da evapotranspiração da cultura (ETc) em condições de campo e ambiente protegido em Arapiraca-AL em função dos dias após o transplante.

Observa-se que a evapotranspiração da cultura da pimenteira em condições de campo obteve níveis mais elevados da evapotranspiração da cultura (ETc) possuindo picos representativos nas fases inicial, intermediária e final do período analisado, com maior ocorrência na fase de floração e frutificação da cultura, atingindo o nível máximo de 9,12 mm.dia ${ }^{-1}$ aos 61 DAT.

Durante o período do experimento a ETc da pimenteira obteve valor de $362,2 \mathrm{~mm}$ e um valor médio de 4,82 mm.dia ${ }^{-1}$. Bezerra e Mesquita (2000) obtiveram evapotranspiração total média de $395,0 \mathrm{~mm}$, na cultura do pimentão com a cultivar Califórnia, no período de 90 DAT, conduzido nos meses de julho a setembro em cultivo de campo do Nordeste brasileiro. Chaves et al. (2005) em experimento com pimenta em Pentecostes - CE encontrou um consumo médio de água durante a condução da cultura de 7,4 mm.dia ${ }^{-1}$ e máximo consumo de água de $8,4 \mathrm{~mm} \cdot \mathrm{dia}^{-1}$. Essa variação na ETc em relação ao presente trabalho, deve-se exclusivamente as variações climáticas da região.

Observando-se os resultados referentes à evapotranspiração da cultura determinados em condições de ambiente protegido, pode-se notar que os níveis mais elevados ocorreram nas fases inicial, intermediária e final do período analisado, com maior ocorrência nas fases inicial e intermediária da cultura, atingindo o nível máximo de 7,16 mm.dia ${ }^{-1}$ aos 33 DAT que compreende o início do florescimento da planta.

Em relação à ETc de todo o período de amostragem, não considerando as precipitações ocorridas, a ETc corresponde a um valor total de 271,4 $\mathrm{mm}$ e um valor médio de 3,61 mm.dia ${ }^{-1}$.

Percebe-se, que a ETc foi sempre superior em condições de campo, evidenciando um consumo maior da planta. Isso se deve ao fato de que as plantas cultivadas fora do ambiente protegido estão mais sujeitos aos elementos climáticos como temperatura e radiação solar, o que provocou um aumento na ETo. Se esses elementos provocam aumento da ETo em condições de campo, seu efeito aumentará também a transpiração da cultura e consequentemente a ETc.

Visando estimar a ETc e o Kc para a cultura da pimenta (Capsicum frutescens L.), nas condições do Nordeste brasileiro, Miranda et al. (2006), obtiveram ETc acumulada de 888 $\mathrm{mm}$, resultado esse que difere dos encontrados, nesse trabalho para os dois ambientes de cultivo. Isso demonstra que mesmo dentro de uma região ocorrem diferenças na demanda da evapotranspiração, e consolida a importância de estudos locais para determinação do manejo adequado da irrigação para as diferentes regiões de produção.

Na Figura 5 podem ser observados os dados de coeficiente da cultura (Kc) que foram determinados através de dois métodos indiretos 
de estimativa de evapotranspiração de referência (ETo), Hargreaves-Samani e Penman-Monteith (FAO-56) em condições de ambiente protegido.

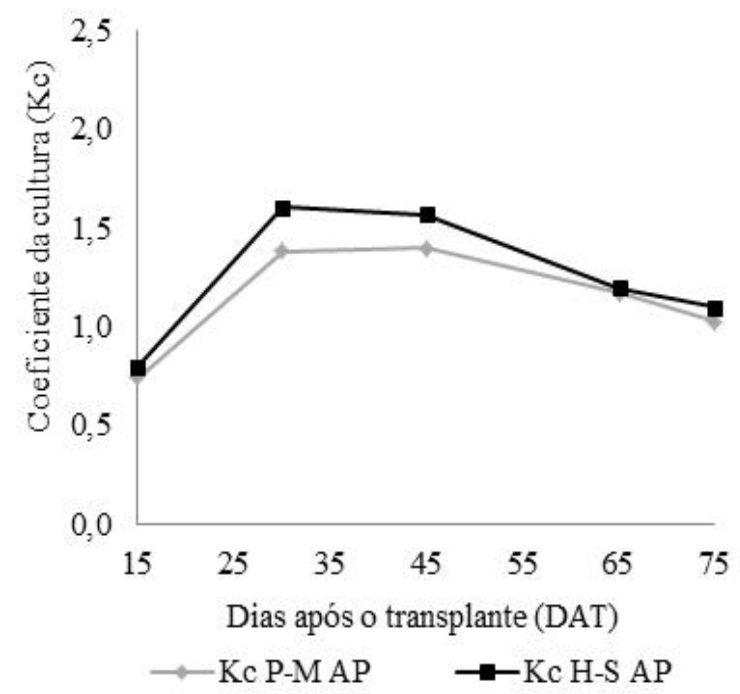

Figura 5. Variação do coeficiente da cultura da pimenteira em condições de ambiente protegido, Arapiraca-AL. Com ETc determinado por PenmanMonteith (FAO-56) (Kc PM) e por HargreavesSamani (Kc HS).

Os valores de coeficiente da cultura (Kc) da pimenta malagueta em condições de ambiente protegido estimado pelo método de Penman-Monteith (FAO-56) aos 15, 30, 45, 65 e 75 dias após o transplante (DAT) variaram em função do consumo diário da cultura, no qual tiveram valores médios de Kc dos três lisímetros correspondentes a 0,74, 1,38, 1,40, 1,17, 1,02 respectivamente. Foram alcançados valores crescentes na fase inicial correspondente aos primeiros 15 DAT, constante na fase de desenvolvimento e floração, de 30 a 45 DAT, em média 1,39, depois decrescendo para 1,17 no início na frutificação, aos 65 DAT e atingindo um mínimo de 1,02 na fase de maturação aos 75 DAT.

Os valores de coeficiente da cultura (Kc) da pimenta malagueta em condições de ambiente protegido estimado pelo método de Hargreaves-Samani aos 15, 30, 45, 65 e 75 dias após o transplante (DAT) variaram em função do consumo diário da cultura, no qual tiveram valores médios de Kc dos três lisímetros correspondentes a 0,79,1,60,1,57, 1,20, 1,10 respectivamente. Foram alcançados valores crescentes na fase inicial correspondente aos primeiros 15 DAT, constante na fase de desenvolvimento e floração, de 30 a 45 DAT, em média 1,59, depois decrescendo para 1,20 no início da frutificação, aos 65 DAT, e atingindo um mínimo de 1,10 na fase de maturação, aos 75 DAT.

Dalmago et al. (2003), estimaram os valores de Kc para a cultura do pimentão conduzido em ambiente protegido, obtiveram valor de 1,06 no fim do ciclo da cultura, próximo ao encontrado nesse trabalho.

Os valores de coeficiente da cultura (Kc) da pimenteira em condições de campo com ETo estimado pelo método Penman-Monteith (FAO-56) e Hargreaves-Samani aos 15, 30, 45, 65 e 75 dias após o transplantio (DTA) podem ser vistos na Figura 6.

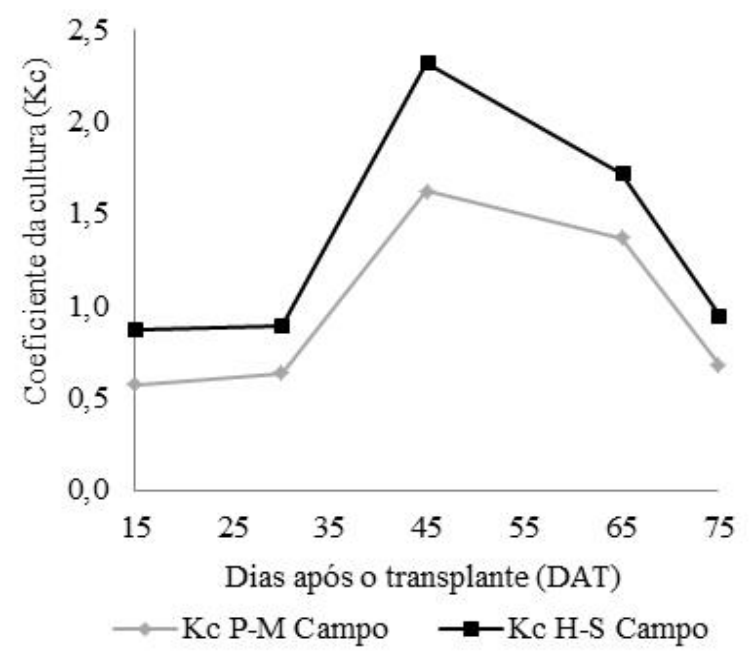

Figura 6. Variação do coeficiente da cultura da pimenteira em condições de campo, Arapiraca-AL.

Com ETo determinado por PenmanMonteith (FAO-56) foram alcançados valores de kc constantes na fase inicial $(0,63)$ correspondente aos primeiros 15 DAT, crescentes na fase de desenvolvimento e floração aos 45 DAT $(1,62)$ chegando a 1,37 no início da frutificação, aos 65 DAT, e decrescendo para 0,68 na fase de maturação, aos 75 DAT.

Os valores de coeficiente da cultura (Kc) da pimenteira em condições de campo estimado pelo método de Hargreaves-Samani aos 15, 30, 
45, 65 e 75 dias após o transplante (DAT) variaram em função do consumo diário da cultura. Foram alcançados valores constantes na fase inicial correspondente aos primeiros 15 DAT $(0,89)$ crescentes na fase de desenvolvimento e floração aos 45 DAT, indo de 0,89 a 2,32, chegando a uma constante de 1,72 no início da frutificação, aos 65 DAT, e decrescendo para 0,95 na fase de maturação, aos 75 DAT.

Os valores máximos encontrados corroboram com Miranda et al. (2006) que também encontrou valores máximos de Kc durante os períodos de intensa floração e desenvolvimento dos frutos.

Comparando-se os valores de coeficiente da cultura $(\mathrm{Kc})$ da pimenteira pelo método de

\section{CONCLUSÕES}

$\mathrm{Na}$ falta das variáveis necessárias para determinação da ETo pelo método padrão pode se utilizar o método de HargreavesSamani para determinação da ETo para essa região, sendo necessária a correção com a equação determinada neste trabalho.

$\mathrm{O}$ Kc para cultivo da pimenta malagueta em condições de ambiente protegido recomendado para a região é 0,74 aumentando até 1,38 até os 30 DAT, 1,39 dos 30 aos 45 DAT, decrescendo até 1,17 dos 45 aos 65 DAT e decrescendo até 1,02 aos 75 DAT.

O Kc para cultivo da pimenta malagueta em condições de campo recomendado para a região é 0,63 até os $30 \mathrm{DAT}$, crescente até 1,62 dos 30 aos 45 DAT, decrescendo até 1,37 dos 45 aos 65 DAT e decrescendo até 0,68 aos 75 DAT.

\section{REFERÊNCIAS}

ALLEN, R. G.; PEREIRA, L. S.; RAES, D; SMITH, M. Crop evapotranspiration Guidelines for computing crop water requirements - FAO Irrigation and drainage paper 56. FAO, Roma, v. 300, p. 5190, 1998.
Penman-Monteith (FAO-56), verifica-se que houve uma superestimativa dos valores quando usado para determinar a ETo pelo método de Hargreaves-Samani tanto em ambiente protegido quanto no campo. Como o método de Hargreaves-Samani produz valores de ETo superestimados a relação ETc/ETo também aumenta, obtendo-se dessa forma valores de Kc mais elevados.

Em relação aos ambientes, nota-se que $\mathrm{o}$ Kc em condições de campo de uma forma geral foi maior que $o$ encontrado em condições de ambeinte protegido. O que corrobora com os dados de ETo e ETc que também foram maiores nessa mesma condição.

BARROCA, M. V.; BONOMO, R.; FERNANDES, A. A.; SOUZA, J. M. Lâminas de irrigação nos componentes de produção das pimentas 'De cheiro' e 'Dedo-deMoça. RevistaAgro@mbiente on-line, v. 9, n. 3, p. 243-250, 2015.

BEZERRA, J. M.; MOURA, G. B. A.; FRANÇA, Ê. F.; LOPES, P. M. O.; SILVA, B. B. Estimativa da evapotranspiração de referência diária para Mossoró (RN, Brasil). Revista Caatinga, v. 27, n. 3, p. 211-220, 2014.

CHAVES, S. W. P.; AZEVEDO, B. M.; MEDEIROS, J. F.; BEZERRA, F. M. L.; MORAIS, N. B. Evapotranspiração e coeficiente de cultivo da pimenteira em lisímetro de drenagem. Revista Ciência Agronômica, v. 36, n. 3, p. 262-267, 2005.

COSTA, T. V.; TARSITANO, M. A. A.; CONCEIÇÃO, M. A. F. Caracterização social e tecnológica da produção de uvas para mesa em pequenas propriedades rurais da região de Jales-SP. Revista Brasileira de Fruticultura, v. 34, n. 3, p. 766-773, 2012.

DALMAGO, G. A.; HEELWEIN, A. B.; BURIOL, G. A.; LUZZA, J.; TAZZO, I. F.; 
TRENTIN, G. Evapotranspiração máxima e coeficiente da cultura do pimentão em estufa plástica. Revista Brasileira de Agrometeorologia, v. 11, n. 7, p. 33-41, 2003.

DUTRA, F. L. A.; BRANCO, I. G.; MADRONA, G. S.; HAMINIUK, C. W. I. Avaliação sensorial e influência do tratamento térmico no teor de ácido ascórbico de sorvete de pimenta. Revista Brasileira de Tecnologia Agroindustrial, v. 4, n. 2, p. 243-251, 2010.

EMBRAPA - Centro Nacional de Pesquisas de Solo. Sistema Brasileiro de Classificação de Solos. 2 ed. Rio de Janeiro, 2006, 306 p.

FAO. Food and Agriculture Organization of the United Nations. 2016. Disponível em: $<$ http://faostat3.fao.org/browse/Q/QC/E $>$.

Acesso em: 15 abr. 2016.

FIGUEIRÊDO, V. B.; MEDEIROS, J. F. D.; ZOCOLER, J. L.; ESPINOLA SOBRINHO, J. Evapotranspiração da cultura da melancia irrigada com água de diferentes salinidades. Revista Engenharia Agrícola, Jaboticabal, v. 29, n. 2, p. 231-240, 2009.

GONÇALVES, F. M.; FEITOSA, H. O.; CARVALHO, C. M.; GOMES FILHO, R. R.; VALNIR JUNIOR, M. Comparação de métodos da estimativa da evapotranspiração de referência para o município de SobralCE. Revista Brasileira de Agricultura Irrigada, v. 3, n. 2, p. 71-77, 2009.

LIMA, E. M. C.; CARVALHO, J. A. C.; REZENDE, F. C.; THEBALDI, M. S.; GATTO, R. F. Rendimento da pimenta Cayenne em função de diferentes tensões de água no solo. Revista Brasileira de Engenharia Agrícola e Ambiental, v. 17, n.11, p. 1181-1187, 2013.

LIMA JUNIOR, J. C.; ARRAES, F. D. D.; OLIVEIRA, J. B.; NASCIMENTO, F. A. L.; MACÊDO, K.G. Parametrização da equação de Hargreaves e Samani para estimativa da evapotranspiração de referência no Estado do Ceará, Brasil. Revista Ciência Agronômica, v. 47, n. 3, p. 447-454, 2016.
MEDEIROS, G. A.; ARRUDA, F. B.; SAKAI, E. Relações entre o coeficiente de cultura e cobertura vegetal do feijoeiro: erros envolvidos e análises para diferentes intervalos de tempo. Acta Scientiarum Agronomy, v. 26, n. 4, p. 513-519, 2004.

MIRANDA, F. D.; GONDIM, R. S.; COSTA, C. A. G. Evapotranspiration and crop coefficients for tabasco pepper (Capsicum frutescens L.). Agricultural Water Management, v. 82, n. 2, p. 237-246, 2006.

MIRANDA, W. L.; CARVALHO, L. G.; NETO, P. C.; SANTOS, P. A. B. Utilização do lisímetro de drenagem para obtenção do "Kc" da mamoneira em plantio adensado. Revista Verde de Agroecologia e Desenvolvimento Sustentável, v. 11, n. 1, p. 08-13, 2016.

PAES, H. M. F.; BARBARA, E. S.; SOUSA, E. F. Determinação da demanda hídrica do quiabeiro em Campos dos Goytacazes, RJ. Revista Ciência Agronômica, v. 43, n. 2, p. 256-261, 2012.

PANDEY, A. K.; SINGH, A. K.; KUMAR, A.; SINGH, S. K. Effect of drip irrigation, spacing and nitrogen fertigation on productivity of Chilli (Capsicum annuum L.). Environment \& Ecology, v. 31, n. 1, p. 139-142, 2013.

PEREIRA, A. R.; VILA NOVA, N. A.; SEDYIAMA, G. C. Evapotranspiração. FEALQ, Picaricaba, Brasil, 1997.183 p.

POZZOBON, M. T.; SOUZA, K. R. R.; CARVALHO, S. I. C.; REIFSCHNEIDER, F. J. B. Meiose e viabilidade polínica em linhagens avançadas de pimenta. Horticultura Brasileira, v. 29, n. 2, p. 212-216, 2011.

SILVA, L. C.; RAO, T. V. R. Avaliação de métodos para estimativa de coeficientes da cultura de amendoim. Revista Brasileira de Engenharia Agrícola e Ambiental, v. 10, n. 1, p. 28-131, 2006.

SILVA, M .G., OLIVEIRA, I. D. S., CARMO, F. F., LÊDO, E. R. F., SILVA FILHO, J.A. Estimativa da evapotranspiração de referência 
Santos et al.

pela equação de Hargreaves-Samani no estado do Ceará, Brasil. Revista Brasileira de
Engenharia de Biossistemas, v.9, n. 2, p. 132141, 2015. 